\title{
Acid extraction as a predictive tool of Radiocaesium Interception Potential (RIP) in a worldwide scale
}

\author{
L. Vandebroek ${ }^{1,2}$, M. Van Hees ${ }^{2}$, B. Delvaux ${ }^{1}$, O. Spaargaren ${ }^{3}$ and Y. Thiry ${ }^{2}$ \\ ${ }^{1}$ Unité des Sciences du Sol, Université Catholique de Louvain, \\ 1348 Louvain-la-Neuve, Belgium \\ ${ }^{2}$ Biosphere Impact Studies, The Belgian Nuclear Research Center, 2400 Mol, Belgium \\ ${ }^{3}$ International Soil Reference and Information Center, 6701 AR Wageningen, \\ The Netherlands
}

\begin{abstract}
The extent of radiocaesium in soil is very important to appreciate the risk of its recycling by the vegetation and thus the risk of food chain contamination. An intrinsic soil parameter, the radiocaesium interception potential (RIP), could be used to measure this retention. In this study, we tested the possibility to predict the RIP starting from a simple acid extraction in widely different soils coming from the whole world and pertaining to various soil reference groups of the WRB/FAO world soil classification. Our results show that a simple acid extraction could be used as an operational test to estimate the RIP whatever the soil type.
\end{abstract}

\section{INTRODUCTION}

After atmospheric deposition, radiocaesium accumulates rapidly in the topsoil because of its selective adsorption on soil particles, largely ruled by weathered micaceous minerals [1]. The extent of ${ }^{137} \mathrm{Cs}$ retention in soil is very important in order to appreciate the risk of its recycling by the vegetation and the potential of foodchain contamination. Various experimental approaches were used to quantify that retention leading to different conceptual coefficients. One of them, the Radiocaesium Interception Potential (RIP - [2]), initially established to measure the radiocaesium fixation on soil particles, has the particularity to be an intrinsic soil parameter that can be rapidly determined in standardized experimental conditions.

The RIP method was initially used to characterize the ${ }^{137} \mathrm{Cs}$ adsorption capacity of temperate soils containing micas. In a first time, tropical and sub-tropical soils were largely overlooked. However, Joussein et al. [3] have showed that African volcanic soils devoid of micas could also selectively retain radiocaesium and thus have a RIP. In this study, we verify the relation between RIP and retention properties of radiocaesium. We also test the possibility to predict the RIP starting from a simple acid extraction.

\section{MATERIALS AND METHODS}

\subsection{A worldwide soil collection}

A collection of 88 surface soil samples from the International Soil Reference and Information Center (ISRIC, Wageningen) was used to measure ${ }^{137} \mathrm{Cs}$ retention properties and also RIP. These soils were chosen to be representative of major soil types in agriculture on a worldwide scale and to cover different climatic zones. These soils came from 24 lands and pertained to 17 different soil reference groups according to the World Reference Base for Soil Resource [4]. 


\subsection{RIP measurements}

RIP was measured in a well defined ionic scenario according to a procedure adapted from [5]. One $\mathrm{g}$ of each soil sample ( 3 replicates) was introduced in a dialysis bag with $5 \mathrm{ml}$ of a $\mathrm{KCl} 0,5 \mathrm{M}-\mathrm{CaCl}_{2} 10^{-4} \mathrm{M}$ equilibration solution (Potassium Adsorption Ratio $(\mathrm{PAR})=0,05 \mathrm{mmol}^{1 / 2} \mathrm{~L}^{-1 / 2}$ ). The solution was changed 10 times during 7 days. During equilibration, all PE bags were agitated 2 hours each 12 hours. Each dialysis bag was then transferred in a $100 \mathrm{ml} \mathrm{PE}$ bag filled with $95 \mathrm{ml}$ of the $\mathrm{KCl}-\mathrm{CaCl}_{2}$ solution labeled with carrier-free ${ }^{137} \mathrm{CsCl}$. These bags were shaked 2 hours each 12 hours. After 5 days, aliquots of $20 \mathrm{ml}$ were taken and ${ }^{137} \mathrm{Cs}$ activity was determined by gamma-counting.

The RIP $\left(\mu \mathrm{mol} \cdot \mathrm{g}^{-1}\right)$ was defined by the relation:

$$
\mathrm{RIP}=\mathrm{K}_{\mathrm{C}} *[\mathrm{FES}]=\mathrm{K}_{\mathrm{D} \mathrm{s}}^{\mathrm{Cs}} *\left[\mathrm{~K}^{+}\right]
$$

where [FES] is the capacity of Frayed Edge Sites with high adsorption selectivity for $\mathrm{Cs}^{+}, \mathrm{K}_{\mathrm{C}}$ is the ${ }^{137} \mathrm{Cs}-\mathrm{K}$ selectivity coefficient on these sites, $\mathrm{K}_{\mathrm{D}}^{\mathrm{Cs}}$ is the ${ }^{137} \mathrm{Cs}$ solid-liquid distribution coefficient and $\left[\mathrm{K}^{+}\right]$is the concentration of $\mathrm{K}$ in solution.

\subsection{Acid extraction}

A sub-sample of the 88 soils was also contaminated by hand shaking. In order to quantify ${ }^{137} \mathrm{Cs}$ retention in the long term, each soil sample was submitted to 10 drying-wetting cycles in order to simulate the ${ }^{137} \mathrm{Cs}$ ageing in soil [6]. The fraction of acid extractable ${ }^{137} \mathrm{Cs}$ was determined following ${ }^{137} \mathrm{Cs}$ desorption with $\mathrm{HCl} 10^{-1} \mathrm{M}$ during 24 hours.

\section{RESULTS AND DISCUSSION}

\subsection{Range of measured RIP values}

The soil collection we used involved a large set of soil groups with very diverse properties and was found to cover a maximum range of adsorption selectivity for radiocaesium in terms of RIP. In fact, the measured RIP values extended on five orders of magnitude. These RIP values ranged from $1.8 \mu \mathrm{mol} \cdot \mathrm{g}^{-1}$ in a Malaysian humic podzol to $13343 \mu \mathrm{mol} \cdot \mathrm{g}^{-1}$ in a Nicaraguan ferric luvisol, which are respectively the smallest and the highest RIP values never found for a soil to our knowledge. Figure 1 represents the confidence interval $(\alpha=0.05)$ and optima of RIP for each major reference soil group represented in our collection. Obviously only 3 groups of soil were characterized by a very low RIP: Podzols, Andosols and Ferralsols.

\subsection{Relation between RIP and ${ }^{137} \mathrm{Cs}$ retention in the soil}

Figure 2 presents the fraction of acid-extractable radiocaesium (AER) as a function of RIP values for the different soils considered. The desorption yields decreased with increasing RIP, the decrease being particularly important in acid extraction for RIP values $<2000$.

Results shown in Figure 2 implied the existence of a relationship between RIP and AER and thus confirmed the link between the RIP and the radiocaesium retention in soil. Using transformations to normalize at once the RIP and the AER, we observed effectively a highly significant ( $\mathrm{P}$-Value $<0.001$ ) linear relation between the square root of RIP and the logarithm of AER. This relationship, shown in Figure 3, is characterized by a correlation coefficient of $\mathrm{R}=-0.905(\mathrm{~N}=88)$.

According to the results of the linear regression, the RIP could be estimated from the equation:

$$
\mathrm{RIP}=(-31.701 * \log (\text { AER })+58.886)^{2}
$$




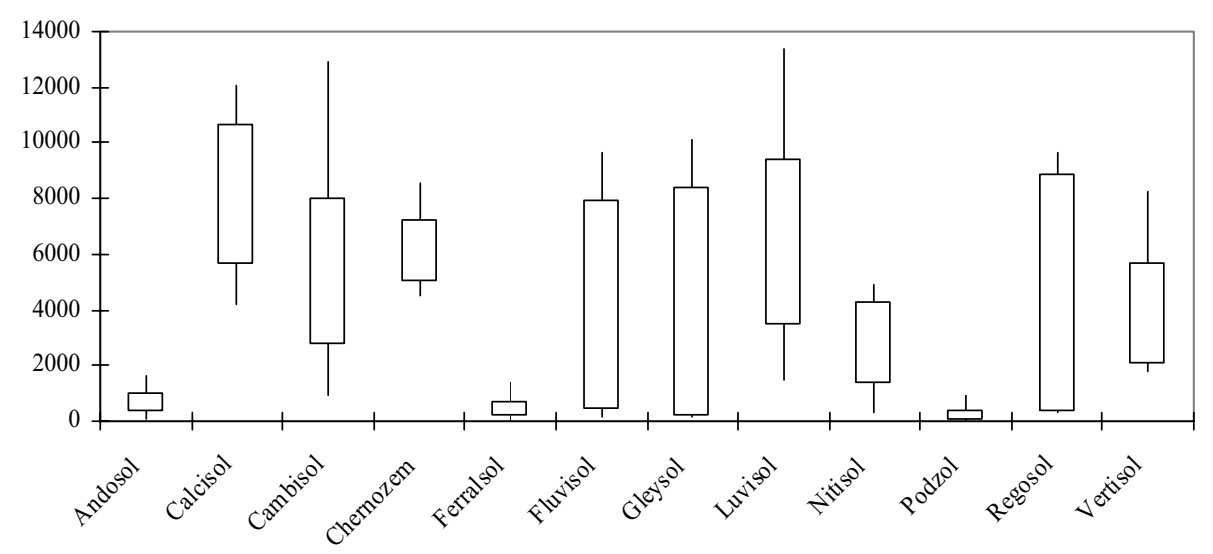

Figure 1. Confidence interval and optima of RIP $\left[\mu \mathrm{mol} \cdot \mathrm{g}^{-1}\right]$ for major reference soil groups.

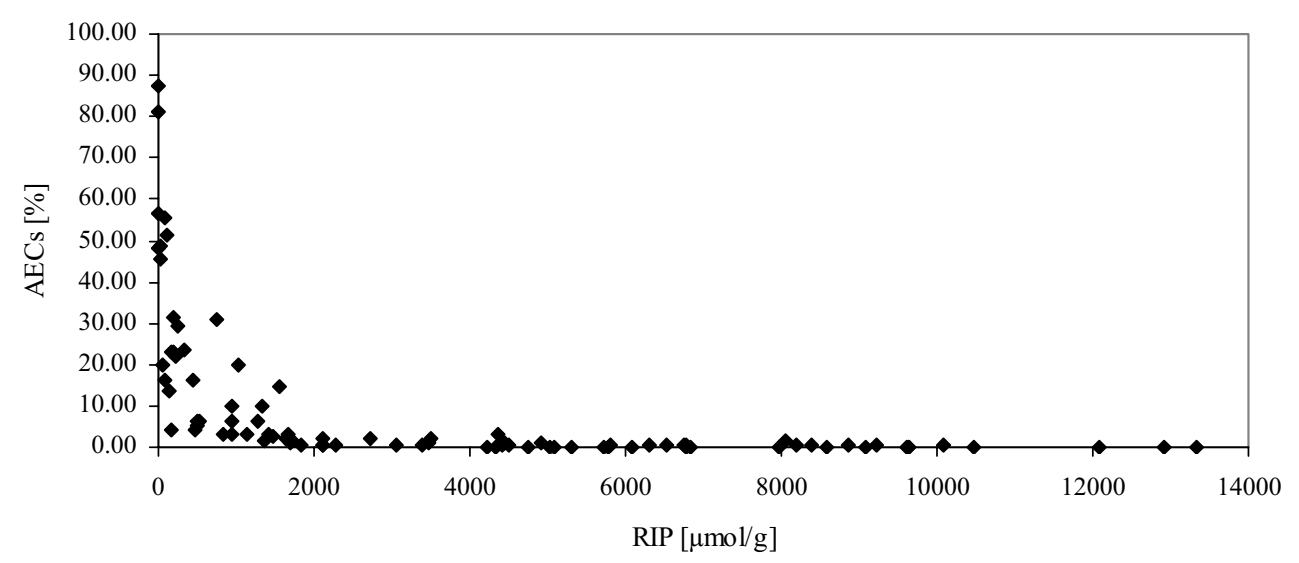

Figure 2. Relation between RIP $\left[\mu \mathrm{mol} \cdot \mathrm{g}^{-1}\right]$ and percentage of acid-extractable ${ }^{137} \mathrm{Cs}$.

Comparison of measured and modeled RIP values resulted in a determination coefficient $\mathrm{R}^{2}$ of 0.736 $(\mathrm{N}=88)$. We defined the error percentage (\% error) as the ratio:

$$
\left(\mathrm{RIP}_{\text {predicted }}-\mathrm{RIP}_{\text {observed }}\right) / \mathrm{RIP}_{\text {observed }} * 100
$$

A positive $\%$ error meant an over-estimation of the RIP while a negative \% error resulted in an underestimation of the RIP. The $\%$ error goes from $-87 \%$ to $764 \%$. The largest error percentages were observed in the lowest range of RIP. Indeed, the $\%$ error goes from $-87 \%$ to $+764 \%$ for the range of RIP $<2000 \mu \mathrm{mol} \cdot \mathrm{g}^{-1}$ while it goes from $-65 \%$ to $+123 \%$ for the range of RIP $>2000 \mu \mathrm{mol} \cdot \mathrm{g}^{-1}$. This finding could be explained by the fact that below a RIP of $2000 \mu \mathrm{mol} \cdot \mathrm{g}^{-1}$, the quantities of radiocaesium desorbed by the $\mathrm{HCl}$ solution were higher and more variable than for a $\mathrm{RIP}$ above $2000 \mu \mathrm{mol} \cdot \mathrm{g}^{-1}$.

The range of error percentages which characterize $50 \%$ of the predicted RIP values may be defined by the interval between the first and the third quartile. This range of $\%$ error goes from -29 to +67 . When considering only the RIP values higher than $2000 \mu \mathrm{mol} \cdot \mathrm{g}^{-1}$, the interval of $\%$ error is reduced between -31 and $+26 \%$. However, this interval increased from -21 to $+128 \%$ for the RIP less than $2000 \mu \mathrm{mol} \cdot \mathrm{g}^{-1}$. That would mean that deducing a realistic estimation of RIP whatever the soil 


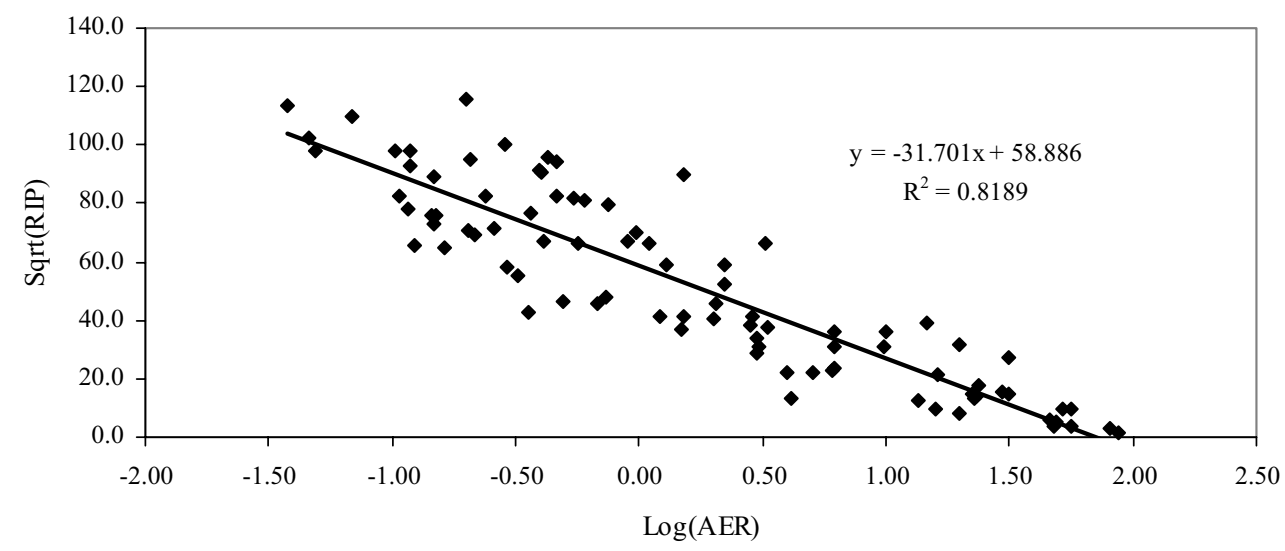

Figure 3. Plot of the square root of RIP as a function of $\log (\mathrm{AER})$.

properties could be achieved through a simple acid extraction. All these results must be confirmed by an independent data base.

\section{CONCLUSIONS}

The proposed scale of RIP values was higher than those previously published. It was shown to embrace all possible cases of agricultural soils contamination including those areas, and especially the developing countries, where data is scarce or missing. Our results showed for the first time that a simple acid extraction could be used as an operational test to estimate the RIP whatever the soil type and the origin of the soil.

A next step will imply the link between RIP, AER and ${ }^{137} \mathrm{Cs}$ transfer to plant.

\section{Acknowledgments}

We are grateful to Hildegarde Vandenhove (SCK-CEN, Belgium) and Xavier Draye (UCL, Belgium) for useful discussions. We also thank Ad Van Oostrum (ISRIC, The Netherlands) for his help in preparing the soil collection.

\section{References}

[1] Maes E., Delvaux B. and Thiry Y., European Journal of Soil Science 49 (1998) 133-140.

[2] Cremers A., Elsen A., De Preter P. and Maes A., Nature 335 (1988) 247-249.

[3] Joussein E., Kruyts N., Righi D., Petit S. and Delvaux B., Soil Science Society of America Journal 68 (2004) 313-319.

[4] FAO, ISRIC, ISSS, World reference base for soil resources (FAO, Rome, Italy, 1998).

[5] Wauters J., Elsen A., Cremers A., Kolopnev A.V., Bulgakov A.A. and Comans R.N.J., Applied Geochemistry 11 (1996) 589-594.

[6] Noordijk H., van Bergeijk K.E., Lembrechts J. and Frissel M.J., Journal of Environmental Radioactivity 15 (1992) 277-286. 